\title{
EVALUASI Hg, Cd, Co, Cr, DAN As DALAM SAMPEL PRODUK AGROINDUSTRI BERDASARKAN KEPUTUSAN BPOM DAN ADI (ACCEPT DAILY INTAKE)
}

\author{
Sri Murniasih, Agus Taftazani \\ PTAPB-BATAN, No. 21 Kotak Pos 6101 ykbb Yogyakarta 55281 \\ unie_rhmt@yahoo.co.id
}

Diterima 16 Oktober 2012, diterima dalam bentuk perbaikan 28 Desember 2012, disetujui 3 Januari 2013

\begin{abstract}
ABSTRAK
Telah dilakukan evaluasi kadar logam berat ( $\mathrm{Hg}, \mathrm{Cd}, \mathrm{Co}, \mathrm{Cr}$ dan $\mathrm{As})$ dalam sampel produk agroindustri, kemudian dibandingkan dengan baku mutu sesuai dengan Keputusan BPOM (Badan Pengawas Obat dan Makanan) no. 03723/B/SKVII/89 dan batas ambang konsumsi harian logam berat dalam tubuh menurut ketentuan ADI (Accept Daily Intake). Sampel produk agroindustri yang dianalisis dalam penelitian ini adalah Teh, Coklat Bubuk, Kopi bubuk, Gula tebu dan Susu Bubuk masing-masing 3 sampel yang diperoleh dari Jawa Barat, Jawa Tengah, Jawa Timur. Sampel, standar primer (SRM), dan standar sekunder masing-masing sebanyak 0,1 gram dimasukkan dalam polietilen vial dan diiradiasi bersama-sama dalam reaktor riset Kartini pada fasilitas iradiasi Lazy Susan selama 2 × 6 jam dengan fluks neutron $1,05 \times 10^{11} \mathrm{n} . \mathrm{cm}^{-2} . \mathrm{s}^{-1}$. Sampel dan standar yang sudah didinginkan 2 sampai 20 hari lalu dicacah dengan menggunakan spektrometer-y dengan detektor $\mathrm{Ge}(\mathrm{Li})$ Ortec serta software Maestro 92 selama 3000 detik. Berdasarkan pada SK BPOM, hasil analisis logam berat pada berbagai sampel agroindustri dapat diketahui bahwa hanya kadar Hg dalam sampel K.1 sebesar 3,719 $\mu \mathrm{g} / \mathrm{g}$ yang melebihi batas ambang baku mutu $(0,03 \mu \mathrm{g} / \mathrm{g})$. Berdasarkan batas ambang konsumsi harian logam berat dalam tubuh menurut ketentuan ADI yang dikeluarkan oleh FAO/WHO, maka dapat diketahui bahwa hanya kadar unsur $\mathrm{Hg}$ dalam sampel $\mathrm{K} .1$ dan kadar unsur As dalam sampel T.1 yang melebihi batas ambang ADI. Jika dibandingkan dengan hasil analisis dari berbagai Negara, kandungan $\mathrm{Hg}, \mathrm{As}, \mathrm{Cr}, \mathrm{Cd}$ dan Co pada semua sampel agroindustri yang dianalisis relatif lebih tinggi.
\end{abstract}

Kata kunci: logam berat, produk agroindustri, instrumen analisis aktivasi neutron

\section{ABSTRACT}

The evaluation concentration of heavy metals ( $\mathrm{Hg}, \mathrm{Cd}, \mathrm{Co}, \mathrm{Cr}$ and $\mathrm{As}$ ) in agro-industry product samples, and compared with the quality standard according to the decree of The National Drug and Food of Agency (NDFA) no. 03723/B/SKVIII/1989 and threshold daily limit intake of heavy metals in the body according to the provisions of $\mathrm{ADI}$ (Accept Daily Intake). Agro-industry product samples analyzed in this study were tea, chocolate powder, coffee powder, sugar and milk powder, 3 samples each obtained from West Java, Central Java, East Java. Samples, The primary standard (SRM), and secondary standards 0.1 grams weight each put in polyethylene vials and together with all samples were irradiated in Lazy Susan, irradiation facility of Kartini research reactor for $2 \times 6$ hours with neutron flux of $1.05 \times 10^{11} \mathrm{n} . \mathrm{cm}^{-2} \cdot \mathrm{s}^{-1}$. Samples and standards then were cooled for 2 to 20 days and then measured by using y-spectrometer with detector Ge (Li) ORTEC and Maestro 92 software for 3000 seconds. Based on SK BPOM, the analysis of heavy metals in various samples of agro-industries can be seen that only concentration of $\mathrm{Hg}$ in samples $\mathrm{K} .1$ is $3.719 \mu \mathrm{g} / \mathrm{g}$, which exceeds the threshold quality standard $(0.03 \mu \mathrm{g} / \mathrm{g})$. Based on the threshold of daily consumption of heavy metals in the body according to the provisions of ADI issued by FAO / WHO, it is known that only Hg concentration in samples K.1 and As concentration in sample T.1 That exceeds the ADI threshold. The results when compared to the analysis of the various countries are higher for the heavy metal contents.

Key words: heavy metals, agroindustry products, instrument neutron activation analysis. 


\section{PENDAHULUAN}

Kemajuan ilmu pengetahuan dan teknologi di Indonesia telah membawa perubahan yang cepat pada berbagai industri, salah satunya agroindustri. Hasil industri pertanian seperti gula, tembakau, bijih kopi dapat diolah menjadi produk agroindustri yang mempunyai nilai tambah dan komoditas perdagangan tinggi. Di Indonesia kasus pencemaran dalam pangan semakin meningkat dan sebagian mengandung logam berat melebihi nilai ambang batas baku mutu pada produk industri. Pencemaran dalam pangan oleh logam merkuri terjadi pada buah dan sayuran di Pongkor pada tahun 2001 di atas nilai batas ambang $0,04 \mathrm{mg} / \mathrm{kg}$ berdasarkan ketentuan BPOM No. 03725/B/SKNII/1989, serta ikan yang memiliki kandungan merkuri sebesar $0,22 \mathrm{mg} / \mathrm{Kg}$ di Sungai Kapuas(1). Penggunaan produk-produk industri dapat mengakibatkan resiko pada kesehatan dan keselamatan konsumen, apabila produk-produk tersebut rusak atau terkontaminasi oleh bahan berbahaya. Pemerintah melalui Balai Pengawas Obat dan Makanan (BPOM) telah membuat peraturan perundang-udangan tentang batas maksimal kandungan logam berat dalam produk yang telah dipasarkan dan dikonsumsi oleh masyarakat. Salah satu produk industri padat yang banyak dikonsumsi oleh masyarakat dan sangat berhubungan dengan kesehatan adalah produk agroindustri.

Logam berat dapat menimbulkan efek terhadap kesehatan bagi manusia tergantung pada bagian tubuh yang terikat logam. Logam berat ini tidak dapat didegradasi maupun dihancurkan dan dapat masuk ke dalam tubuh manusia lewat makanan, air minum, atau udara. Logam berat yang bersifat racun di dalam tubuh akan membahayakan kesehatan bahkan menyebabkan kematian.

Keracunan unsur logam berat merkuri $(\mathrm{Hg})$ dapat menyebabkan bronkitis, sampai rusaknya paru-paru. Keracunan kadmium (Cd) dapat menyebabkan kanker paru-paru, kerusakan ginjal dan hati, merusak tulang (osteomalacia, osteoporosis). Keracunan kobalt (Co) dapat menyebabkan kelainan pada jantung seperti gagal jantung, dan naiknya tekanan darah. Keracunan kromium $(\mathrm{Cr})$ berakibat buruk terhadap sistem saluran pernafasan, kulit, pembuluh darah, dan ginjal. Sedangkan keracunan arsen (As) dapat menimbulkan kegagalan fungsi sumsum tulang, menurunnya sel darah, gangguan fungsi hati, ginjal, gangguan pernafasan, kerusakan pembuluh darah, dan gangguan saluran pencernaan(2).

Analisis logam berat dalam produk agroindustri dapat dilakukan dengan berbagai macam metode di antaranya dengan metode Analisis Aktivasi Neutron (AAN). Metode AAN dipilih karena dapat menganalisis sampel dalam bentuk fisik padat, cair maupun gas, dapat menganalisis beberapa unsur secara serempak, dapat menganalisis beberapa unsur kelumit yang mempunyai kadar sampai orde ppb $\left(10^{-9}\right)$.

Dari uraian di atas, maka perlu diadakan penelitian mengenai analisis kandungan logam berat $(\mathrm{Hg}, \mathrm{Cd}$, $\mathrm{Co}, \mathrm{Cr}$, dan As) dalam berbagai produk agroindustri dan membandingkannya dengan nilai ambang batas baku mutu dengan metode AAN. Penelitian ini bertujuan untuk menganalisis logam berat $(\mathrm{Hg}, \mathrm{Cd}, \mathrm{Co}, \mathrm{Cr}$, dan $\mathrm{As})$ dalam sampel produk agroindustri dari Jawa Timur, Jawa Tengah dan Jawa Barat serta membandingkan kadar logam berat yang terdapat dalam sampel dengan nilai ambang batas produk agroindustri sesuai dengan Standar Industri Indonesia (SII) atau Keputusan BPOM No.03732/B/VII/1989 dan batas maksimum konsumsi harian logam berat dalam tubuh manusia menurut ketentuan ADI (Acceptable Daily Intake) dari FAO/WHO.

\section{METODOLOGI}

\section{Alat-Alat Penelitian}

Alat-alat yang digunakan dalam penelitian ini adalah : reaktor riset Kartini fasilitas iradiasi Lazy Susan, seperangkat spektrometer gamma dengan detektor $\mathrm{Ge}(\mathrm{Li})$ Ortec dengan software Maestro 92, neraca digital OHAUS, oven Memmert, eksikator, almari pengering, mortal dan agart porselin, ayakan 100 Mesh, peralatan gelas, kelongsong dan vial Polyetilene $1 \mathrm{~mL}$.

\section{Bahan-Bahan Penelitian}

Bahan-bahan yang digunakan dalam penelitian ini adalah : sampel agroindrustri (terdiri dari teh hitam, kopi bubuk, susu bubuk, coklat bubuk dan gula tebu yang masing-masing sampel diambil dari daerah Jawa 
Barat, Jawa Tengah, dan Jawa Timur), larutan $\mathrm{HNO}_{3} 65 \%$, SRM (Standard Reference Material) 1573 Tomato Leaves, larutan standar $\mathrm{Hg}, \mathrm{Cd}, \mathrm{Co}, \mathrm{Cr}$, dan As masing-masing 1000 mg/g, serbuk Cellulosa Powder.

\section{Cara Pengambilan Sampel}

Pengambilan sampel untuk penelitian ini digunakan dengan metode sampel acak (simple random sampling). Sampel diambil atau dibeli di supermarket, industri, maupun pasar sebanyak 500 gram kemudian diberi label sesuai nama sampel, lokasi, dan waktu pembelian sampel dan disimpan di almari maupun di almari pendingin.

\section{Preparasi}

\section{Preparasi Vial}

Vial Polyethilene yang akan dipakai untuk iradiasi sebelumnya dipreparasi dengan cara dicuci dengan detergen dan air kemudian dibilas dengan aquades sebanyak 3 kali, direndam dalam larutan $\mathrm{HNO}_{3}$ : aquabides (1:3) selama 24 jam kemudian dicuci kembali dengan aquabidest sebanyak 3-4 kali, setelah itu direndam dalam aseton sambil dikocok perlahan sampai vial bebas dari air dan kotoran. Vial yang bebas air ini dikeringkan dalam almari pengering atau oven $80^{\circ} \mathrm{C}$ dan siap untuk digunakan.

\section{Preparasi Sampel}

Sampel yang berupa susu bubuk, teh hitam, kopi bubuk, coklat bubuk, dan gula tebu diambil masingmasing sebayak 500 gram dalam keadaan kering. Sampel tersebut dihaluskan menggunakan mortal dan agart porselin dan diayak sampai lolos 100 mesh. Sampel dihomogenkan, dan dimasukkan dalam wadah yang bebas kontaminasi serta berlabel. Masing-masing sampel ditimbang seberat 0,1 gram dan dimasukkan dalam vial polyetilene. Vial dimasukkan ke dalam plastik klip yang telah diberi kode sesuai dengan kode sampelnya(3). Masing-masing sampel dibuat 3 buah sampel (triplo). Semua plastik klip yang berisi vial polyetilene dimasukkan ke dalam kelongsong polyetilene untuk diiradiasi.

\section{Preparasi Standar Primer}

Ditimbang serbuk standar primer SRM (Standard Reference Material) 1573 Tomato Leaves sebanyak 0,1 gram dalam vial polyetilene dan dimasukkan ke dalam plastik klip yang telah diberi kode. Vial dalam plastik klip dimasukkan ke dalam kelongsong dan siap diiradiasi (3). Pada penelitian ini standar primer yang digunakan rangkap 3 (triplo).

\section{Preparasi Standar Sekunder}

Larutan standar sekunder yang digunakan adalah larutan standar campuran $\mathrm{Cd}, \mathrm{Cr}$, Co, dan As. Masingmasing larutan standar induk $\mathrm{Cd}$, Co, dan $\mathrm{Cr} 1000 \mu \mathrm{g} / \mathrm{g}$ dari produk Fisher diambil $1 \mathrm{~mL}$ dan $0.5 \mathrm{~mL}$ untuk larutan standar As $1000 \mu \mathrm{g} / \mathrm{g}$ lalu dimasukkan ke dalam labu ukur $100 \mathrm{~mL}$ dan ditambahkan akuabidest sehingga diperoleh larutan standar campuran dengan konsentrasi masing-masing Cd, Co dan $\mathrm{Cr} 10 \mu \mathrm{g} / \mathrm{g}$ serta As $5 \mu \mathrm{g} / \mathrm{g}$. Larutan standar sekunder $\mathrm{Hg}$ dibuat terpisah. Larutan standar induk $\mathrm{Hg} 1000 \mu \mathrm{g} / \mathrm{g}$ dari produk Fisher diambil sebanyak $0,5 \mathrm{~mL}$ lalu dimasukkan ke dalam labu ukur $100 \mathrm{~mL}$ dan ditambahkan akuabides sehingga diperoleh larutan standar $\mathrm{Hg} 5 \mu \mathrm{g} / \mathrm{g}$. Sebanyak 0,1 gram Cellulosa Powder ditimbang, dimasukkan dalam vial dan ditambahkan kedalamnya $1 \mathrm{~mL}$ larutan logam standar sekunder campuran $(\mathrm{Co}, \mathrm{Cr}, \mathrm{Cd}$ dan $\mathrm{As}$ ) tersebut kemudian dikeringkan. Selain itu, ditambahkan $1 \mathrm{~mL}$ larutan $\mathrm{Hg}$ yang telah diencerkan ke dalam 0,1 gram Cellulosa Powder secara terpisah untuk mencegah kontaminasi karena sifat $\mathrm{Hg}$ yang mudah menguap.

Masing-masing larutan standar yang sudah siap dalam vial polyetilene kemudian dimasukkan ke dalam plastik klip yang telah diberi kode. Vial dalam plastik klip tersebut dimasukkan ke dalam kelongsong dan siap diiradiasi(3).

\section{Iradiasi dan Pencacahan}

Semua kelongsong yang berisi sampel, standar primer, standar sekunder dan blanko dimasukkan ke dalam reaktor riset Kartini pada fasilitas iradiasi Lazy Susan. Proses iradiasi dilakukan selama 12 jam dengan fluks neutron sekitar $1,05 \times 10^{11} \mathrm{n} \cdot \mathrm{cm}^{-2} \cdot \mathrm{s}^{-1}$ dalam reaktor riset Kartini daya $100 \mathrm{~kW}$. Semua kelongsong 
didinginkan selama 2 sampai 20 hari (tergantung waktu paruh unsur yang dianalisis) setelah diiradiasi, dan dicacah menggunakan spektrometer gamma, dihitung besarnya spektrum dan dibandingkan antara spektrum sampel, SRM dan standar sekunder untuk menentukan kadar unsur logam berat dalam sampel(3).

\section{Analisis Data}

Data hasil pencacahan yang berupa puncak spektrum gamma beserta nomor salurnya dianalisis secara kualitatif dan kuantitatif. Analisis kualitatif dilakukan untuk mengetahui keberadaan logam berat pada sampel yang diperlukan untuk analisis kuantitatif. Hasil puncak spektrum gamma dicatat nomor salur dan tenaganya yang menunjukkan keberadaan logam berat yang dianalisis dan dicocokan dengan tabel isotop(4) sehingga dapat diketahui logam berat yang terdeteksi pada sampel. Tenaga sinar gamma yang dipancarkan oleh radionuklida adalah salah satu sifat karakteristik dari radionuklida tersebut(5)).

Analisis kuantitatif bertujuan untuk menentukan kadar logam berat yang terdapat dalam sampel dengan metode komparatif yaitu membandingkan kadar logam berat dalam sampel dengan kadar logam berat yang ada dalam standar yang telah diketahui dengan pasti. Standar dan sampel yang telah diiradiasi dicacah dalam waktu yang sama. Untuk menentukan kadar suatu logam berat dalam sampel dihitung dengan persamaan berikut $(3)$ :

$$
\begin{aligned}
& K_{c}=\frac{\left(c p s_{0}\right)_{\text {cuplikan }}}{\left(c p s_{0}\right)_{\text {standar }}} \cdot K_{s} \\
& c p s_{0}=c p s_{t} \cdot e^{\frac{0.693 . t}{T}} \\
& c p s_{t}=\frac{\text { netto }}{t_{\text {cacah }}}
\end{aligned}
$$

Keterangan :

$\mathrm{K}_{\mathrm{C}}=$ kadar unsur dalam sampel $(\mu \mathrm{g} / \mathrm{ml}$ atau $\mu \mathrm{g} / \mathrm{g}$ atau $\mu \mathrm{g} / \mathrm{g})$

$\mathrm{K}_{\mathrm{S}}=$ kadar unsur dalam standar $(\mu \mathrm{g} / \mathrm{ml}$ atau $\mu \mathrm{g} / \mathrm{g}$ atau $\mu \mathrm{g} / \mathrm{g})$

$\mathrm{Cps}_{0}=$ laju cacah pada saat $\mathrm{t}=0$ (cps), yaitu saat penembakan neutron dihentikan

$\mathrm{Cps}_{\mathrm{t}}=$ laju cacah pada saat $\mathrm{t}$ detik (cps)

$\mathrm{t}=$ waktu tunda sampel (jam)

$T$ = waktu paruh unsur (jam)

Netto = hasil pencacahan selama waktu pencacahan

$\mathrm{t}_{\text {cacah }}=$ lama waktu pencacahan (detik)

\section{Uji Validasi}

Untuk menguji keberhasilan hasil pengukuran atau analisis dapat dievaluasi dengan melihat besar keseksamaan (presisi) hasil analisis yang dihitung dengan rumus ${ }^{(3)}$ :

$$
\text { Presisi }=100 \%-\left(\frac{\mathrm{s}}{\mathrm{x}} \times 100 \%\right)
$$

Keterangan :

$\mathrm{x}=$ kadar rata-rata sampel

$\mathrm{s}=$ standar deviasi dari kadar sampel

Untuk menguji kehandalan hasil pengukuran atau hasil analisis dilakukan dengan mencacah standar primer yang diiradiasi bersama dengan sampel dan standar. Standar primer yang digunakan dalam penelitian ini adalah BCR No 62 Trace Elemet In Olive Leaves yang diperlakukan seperti sampel. Ketelitian (akurasi) hasil pengukuran logam berat dalam standar primer dengan sertifikat menggunakan persamaan berikut(3):

$$
\text { Akurasi (\%) }=\left|\frac{\mathrm{ks}-\mathrm{kc}}{\mathrm{ks}}\right| \times 100 \%
$$

Keterangan :

$\mathrm{kc}=$ konsentrasi hasil pengukuran

$\mathrm{ks}=$ konsentrasi dalam sertifikat 
Hasil dari analisis konsentrasi unsur logam berat pada standar primer dibandingkan dengan harga kadar logam berat sejenis yang tercantum dalam sertifikat. Akurasi menunjukkan kedekatan pengukuran terhadap nilai sebenarnya yang tercantum dalam sertifikat.

\section{Figur Of Merit (FOM)}

Figur of merit merupakan besaran yang digunakan untuk memperlihatkan kemampuan alat ukur ${ }^{(4)}$, yang dinyatakan dengan persamaan :

$$
\mathrm{FOM}=\frac{\mathrm{E}^{2}}{\mathrm{~B}}
$$

Keterangan:

$\mathrm{E}=$ efisiensi pencacahan $(\%)$

$\mathrm{B}=$ laju cacah blangko (cps)

\section{Deteksi Pengukuran}

Deteksi suatu pengukuran yang lazim digunakan ada 3 yaitu limit deteksi, limit kritis dan limit determinasi. Limit deteksi merupakan besaran yang dipakai untuk menilai kemampuan sistem pada kondisi tertentu. Cacah terendah yang dapat dideteksi dengan tingkat signifikan 95\% menggunakan persamaan (7). Limit kritis merupakan besaran yang dipakai untuk menilai hasil pencacahan yang dinyatakan terdeteksi atau tidak terdeteksi yang dinyatakan dengan dalam persamaan (8), sedangkan limit determinasi merupakan besaran yang dipakai untuk menilai kemampuan kerja minimum sistem yang dinyatakan dalam persamaan (9)(6).

$$
\begin{aligned}
& \mathrm{L}_{\mathrm{D}}=3,29 \sigma_{\mathrm{b}} \\
& \mathrm{L}_{\mathrm{C}}=1,64 \sigma_{\mathrm{b}} \\
& \mathrm{L}_{\mathrm{Q}}=10 \sigma_{\mathrm{b}}
\end{aligned}
$$

Keterangan:

$L_{D}=$ batas deteksi terendah $(\mathrm{cps}) \mathrm{L}_{Q}=$ batas kerja terendah $(\mathrm{cps})$

$\mathrm{L}_{\mathrm{c}}=$ limit kritis (cps) $\sigma_{b}=$ standar deviasi blangko (cps)

\section{HASIL DAN PEMBAHASAN}

\section{Uji Kestabilan Alat}

Peralatan spektrometer gamma yang digunakan untuk mencacah sampel dan standar harus dapat diandalkan kestabilannya agar menghasilkan analisis yang benar. Pencacahan baru dilakukan setelah didapat hasil yang mantap dengan ketelitian tinggi. Hasil pencacahan untuk menentukan kestabilan alat. Kestabilan alat spektrometer-y di uji dengan metode chi-kuadrat $\left(X^{2}\right)$ pada selang kepercayaan $95 \%$ dengan 10 kali pengukuran sehingga didapat harga tabel sebesar 16,92 . Hasil pencacahan sumber standar multigamma ${ }^{137} \mathrm{C}$ s selama 100 detik dengan 10 kali pengulangan pada kondisi alat yang sama memberikan harga $\chi^{2}$ dihitung adalah 9,41 . Hasil tersebut dapat disimpulkan bahwa $X^{2}$ hitung $\leq X^{2}$ tabel yang artinya alat stabil secara statistik untuk analisis sampel.

\section{Kalibrasi Spektrometer Gamma}

Spektrometri gamma adalah suatu metode pengukuran yang bersifat nisbi (relatif), sehingga sebelum suatu perangkat spektrometer gamma dapat dipakai untuk menentukan aktivitas unsur-unsur logam berat suatu sampel, alat tersebut perlu dikalibrasi terlebih dahulu secara cermat dan teliti.

\section{Kalibrasi Tenaga}

Kalibrasi ini dilakukan dengan mencacah sumber standar multigamma ${ }^{152} \mathrm{Eu}$ selama 300 detik dengan jarak detektor $6 \mathrm{~cm}$. Sumber standar multigamma ${ }^{152} \mathrm{Eu}$ merupakan sumber standar yang tenaga gammanya telah diketahui dengan tepat. Data Kalibrasi tenaga spektrometer gamma menghasilkan persamaan garis $Y=$ $0,5025 \mathrm{X}-0,9864$ dan $R^{2} \approx 1$. 


\section{Kalibrasi Efisiensi}

Kalibrasi efisiensi digunakan untuk meminimalisasi adanya radiasi yang tidak terdeteksi oleh luas penampang dari detektor. Analisis kuantitatif dalam spektrometri-y membutuhkan kalibrasi efisiensi terutama jika analisis kuantitatif dilakukan dengan metode komparatif. Kalibrasi efisiensi dilakukan seperti kalibrasi tenaga dengan aktivitas ${ }^{152} \mathrm{Eu}$ sebesar $1,975.10^{5} \mathrm{dps}$. Data pengukuran menghasilkan persamaan garis $\mathrm{Y}=65,473 \mathrm{X}$ 1,0438 dengan harga $R^{2}$ sebesar 0,967. Berdasarkan kurva kalibrasi efisiensi (Gambar 1) memperlihatkan bahwa koefisian korelasi (r) mempunyai harga 0,9665 yang menyatakan mendekati 1 maka hubungan variabel sangat erat hal ini menunjukkan bahwa alat mempunyai efisiensi yang baik dan layak untuk digunakan.

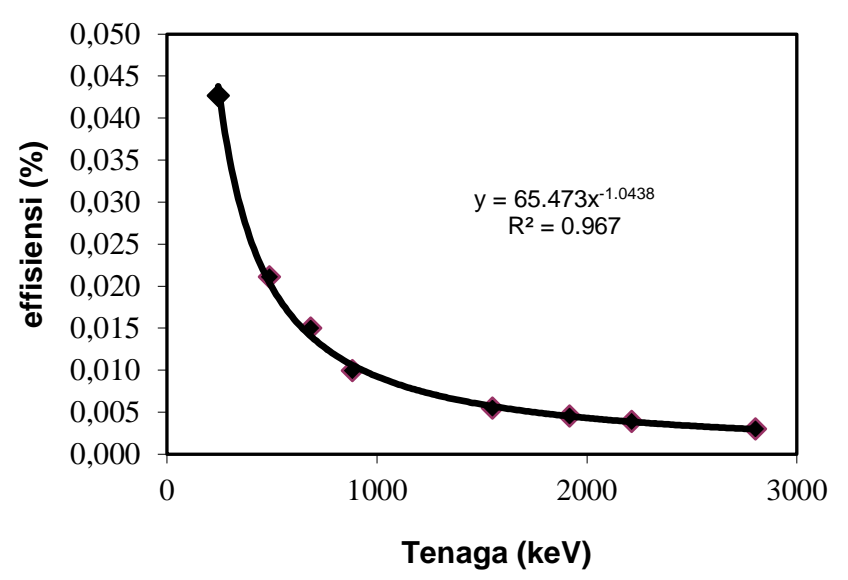

Gambar 1. Kurva kalibrasi efisiensi detektor GeLi ORTEC

\section{Analisis Kualitatif Dan Kuantitatif}

\section{Kandungan Unsur Logam Berat Hg dalam Sampel}

Hasil identifikasi dari unsur logam berat yang ada dalam sampel dapat digunakan untuk analisis kuantitatif untuk mengetahui kadar unsur logam berat pada sampel. Hasil analisis kualitatif unsur logam berat dalam sampel disajikan pada Tabel 1.

Tabel 1. Kandungan Logam Berat dalam Sampel

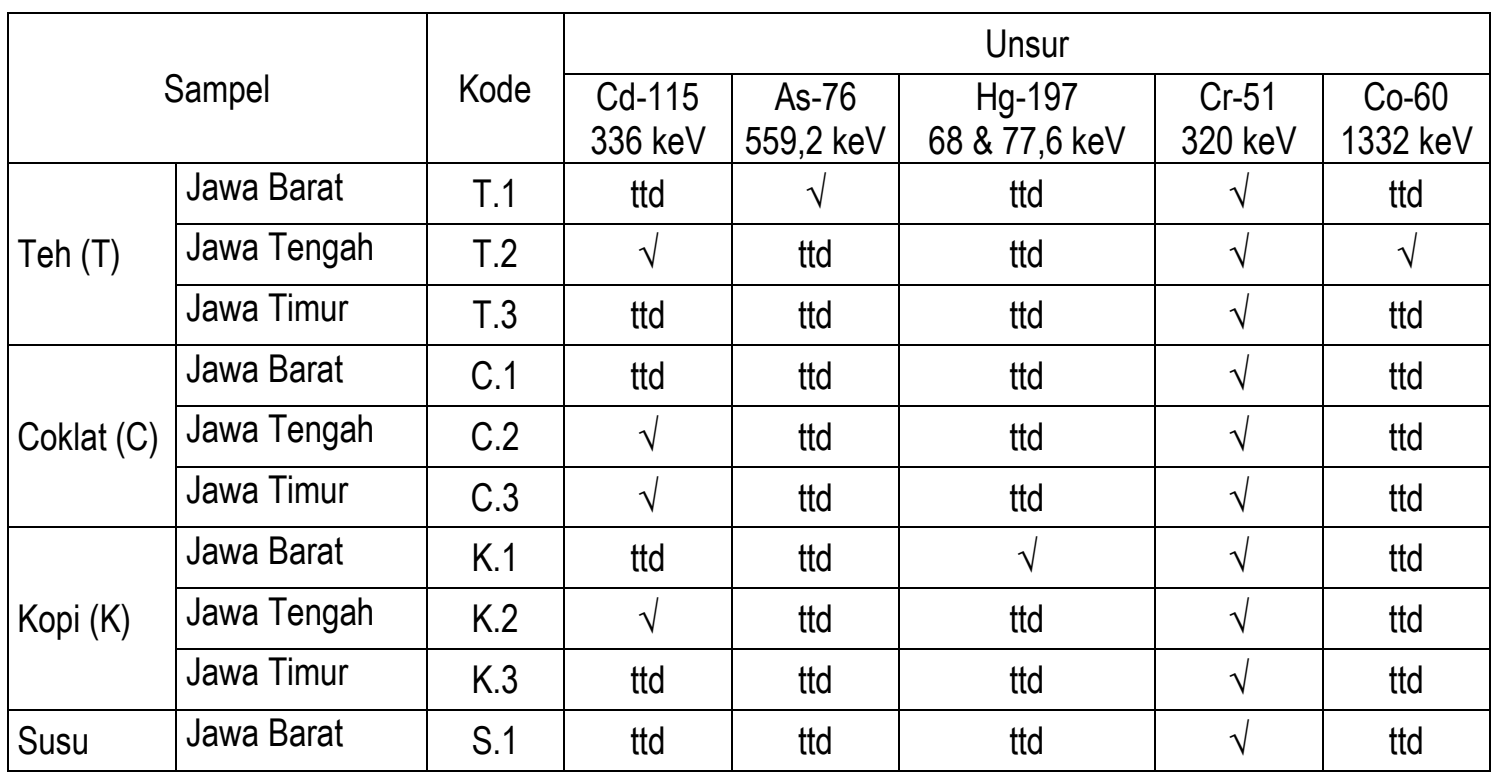




\begin{tabular}{|c|c|c|c|c|c|c|c|}
\hline \multirow{2}{*}{\multicolumn{2}{|c|}{ Sampel }} & \multirow[b]{2}{*}{ Kode } & \multicolumn{5}{|c|}{ Unsur } \\
\hline & & & $\begin{array}{l}\text { Cd-115 } \\
336 \mathrm{keV}\end{array}$ & $\begin{array}{c}\text { As-76 } \\
559,2 \mathrm{keV}\end{array}$ & $\begin{array}{c}\mathrm{Hg}-197 \\
68 \& 77,6 \mathrm{keV}\end{array}$ & $\begin{array}{c}\text { Cr-51 } \\
320 \mathrm{keV}\end{array}$ & $\begin{array}{c}\text { Co-60 } \\
1332 \mathrm{keV}\end{array}$ \\
\hline \multirow[t]{2}{*}{ Bubuk (S) } & Jawa Tengah & S.2 & $\mathrm{ttd}$ & $\mathrm{ttd}$ & $\mathrm{ttd}$ & $\sqrt{ }$ & $\mathrm{ttd}$ \\
\hline & Jawa Timur & S.3 & $\mathrm{ttd}$ & $\mathrm{ttd}$ & ttd & Ttd & $\mathrm{ttd}$ \\
\hline \multirow{3}{*}{$\begin{array}{l}\text { Gula Tebu } \\
\text { (G) }\end{array}$} & Jawa Barat & G.1 & $\sqrt{ }$ & $\mathrm{ttd}$ & $\mathrm{ttd}$ & Ttd & $\mathrm{ttd}$ \\
\hline & Jawa Tengah & G.2 & $\mathrm{ttd}$ & $\mathrm{ttd}$ & $\mathrm{ttd}$ & Ttd & $\mathrm{ttd}$ \\
\hline & Jawa Timur & G.3 & $\sqrt{ }$ & ttd & $\mathrm{ttd}$ & Ttd & $\sqrt{ }$ \\
\hline
\end{tabular}

\footnotetext{
Keterangan:

$\sqrt{ }:$ Terdeteksi

ttd : tidak terdeteksi
}

Logam berat $\mathrm{Hg}$ termasuk logam yang mempunyai daya racun tinggi, jika masuk ke dalam tubuh manusia secara terus menerus dapat menyebabkan kerusakan permanen pada otak, hati dan ginjal. Kadar unsur logam berat $\mathrm{Hg}$ pada energi $77 \mathrm{keV}$ harus lebih besar dari limit deteksi $\mathrm{Hg}\left(L_{D)}\right.$ yaitu 0,2846 $\mu \mathrm{g} / \mathrm{g}$.

Unsur Hg hampir tidak terdeteksi pada semua sampel kecuali sampel Kopi K.1. Kadar Hg yang terdapat dalam sampel K.1 bila dibandingkan dengan baku mutu menurut baku mutu BPOM nilainya di atas batas ambang baku mutu yaitu $0,03 \mu \mathrm{g} / \mathrm{g}^{(7)}$. Sedangkan jika dibandingkan dengan batas toleransi ADI, pemasukan logam berat $\mathrm{Hg}$ ke dalam tubuh adalah $42,9 \mu \mathrm{g}$ per hari. Hasil analisis menunjukkan kadar logam raksa dalam sampel kopi Jawa Barat (K.1) sebesar 3,719 $\pm 0,423 \mu \mathrm{g} / \mathrm{g}$ pada energi $77 \mathrm{keV}$. Apabila rata-rata orang mengkonsumsi kopi 2 kali perhari $\times 20 \mathrm{~g} /$ cangkir (= $40 \mathrm{gram}$ dalam sehari) dan dianggap semua kandungan unsur $\mathrm{Hg}$ masuk ke dalam tubuh maka rata-rata orang menelan $\mathrm{Hg}$ sebesar 133,754 $\mu$ g/hari. Kadar $\mathrm{Hg}$ pada sampel K.1 melampaui batas toleransi yang diizinkan menurut konsep ADI dan melebihi hasil analisis sampel kopi bubuk dari Turki yang terdeteksi adanya $\mathrm{Hg}$ menggunakan metode FAAS dengan konsentrasi $0,061 \pm 0,054 \mu \mathrm{g} / \mathrm{g}^{(12)}$.

Standar baku mutu Negara Mesir(8) menunjukkan bahwa kandungan $\mathrm{Hg}$ tidak boleh lebih dari 0,02 $\mu \mathrm{g} / \mathrm{g}$ dan hasil analisis pada sampel susu dari China dan Jepang(9) tidak terdeteksi adanya kandungan $\mathrm{Hg}$. Sedangkan hasil analisis $\mathrm{Hg}$ pada susu di daerah Italia menunjukkan rata-rata kandungan $\mathrm{Hg}$ pada susu bubuk terdeteksi $0,002 \pm 0,005^{(11)}$. Analisis yang dilakukan peneliti lain pada sampel susu Turki terdeteksi $0,007 \pm 0,003^{(12)}$.

\section{Kandungan Unsur Logam Berat Cd dalam Sampel}

Logam berat cadmium $(\mathrm{Cd})$ masuk ke dalam tubuh terutama melalui makanan yang telah terkontaminasi oleh logam kadmium dikonsumsi. Salah satu contoh terjadinya keracunan logam Cd pada manusia adalah penyakit itai-itai. Penderita biasanya merasa sakit yang sangat pada daerah tulang sehingga biasanya mengeluh penyakit itai - itai. Penyakit ini apabila berlanjut dapat menyebabkan lumpuh dan terjadi patah tulang di beberapa bagian tubuh. $\mathrm{Cd}$ adalah unsur alami yang terdapat pada perut bumi dan banyak ditemukan bersamaan dengan senyawa lain seperti oksigen (oksida kadmium) yang menjadikan $\mathrm{Cd}$ lebih mudah mengendap pada perairan. Logam berat $\mathrm{Cd}$ lebih mudah diakumulasi oleh tanaman dibanding logam berat lainya seperti timbal (Pb). Logam berat $\mathrm{Cd}$ berikatan dengan $\mathrm{Pb}$ dan $\mathrm{Hg}$ sebagai The big Three Heavy Metal yang memiliki tingkat bahaya tertinggi pada kesehatan manusia( ${ }^{(8,9)}$.

Pada Tabel 2 memperlihatkan bahwa kadar unsur logam berat $C d$ terdeteksi pada sampel teh T.2, coklat C.2 dan C.3, kopi K.2 dan gula tebu G.1 dan G.3. Logam Cd terdeteksi pada tenaga 336 keV pada spektrometer gamma.

Kadar $\mathrm{Cd}$ yang terdapat dalam sampel hanya dapat dibandingkan dengan ambang batas dari ADI karena belum ada ambang batas baku mutu dari BPOM. Batas toleransi ADI pemasukan logam berat Cd ke dalam tubuh $60 \mu \mathrm{g} / \mathrm{hari}$. Hasil analisis menunjukkan kadar unsur Cd dalam sampel T.2 sebesar 0,575 $\pm 0,089$ $\mu \mathrm{g} / \mathrm{g}$; sampel C.2 sebesar 1,771 $\pm 0,019 \mu \mathrm{g} / \mathrm{g}$, sampel C.3 sebesar 1,951 $\pm 0,09 \mu \mathrm{g} / \mathrm{g}$; sampel K.2 sebesar

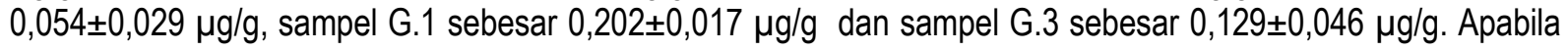


rata-rata orang mengkonsumsi teh perhari adalah 40 gram dalam sehari dan dianggap semua unsur $\mathrm{Cd}$ yang masuk ke dalam tubuh seluruhnya maka rata-rata orang menelan $\mathrm{Cd}$ sebesar $24,165 \mu \mathrm{g} / \mathrm{hari}$; seseorang mengkonsumsi coklat (C.2) sebesar 40 gram dalam sehari maka logam berat $\mathrm{Cd}$ yang masuk ke dalam tubuh sebesar 74,42893 $\mu \mathrm{g} / \mathrm{hari}$; seseorang mengkonsumsi coklat (C.3) sebesar 40 gram dalam sehari maka logam berat Cd yang masuk ke dalam tubuh sebesar 81,994 $\mu \mathrm{g} / \mathrm{hari} ;$ seseorang mengkonsumsi kopi sebesar 40 gram dalam sehari maka logam berat $\mathrm{Cd}$ yang masuk ke dalam tubuh sebesar 2,269 $\mu \mathrm{g} / \mathrm{hari}$; seseorang mengkonsumsi gula tebu sebesar 40 gram dalam sehari maka logam berat $\mathrm{Cd}$ yang masuk ke dalam tubuh sebesar 5,421 $\mu \mathrm{g} / \mathrm{hari}$. Kadar Cd pada sampel teh, kopi, dan gula tidak melampaui batas toleransi yang diizinkan menurut konsep ADI. Namun jumlah kadar pada sampel C.2 dan C.3 melampaui batas toleransi yang diizinkan menurut konsep ADI. Hasil analisis $\mathrm{Cd}$ dalam sampel teh T.1 lebih besar jika dibandingkan dengan hasil penelitian yang telah dilakukan W.Y.Han ${ }^{(10)}$ yaitu konsentrasi $\mathrm{Cd}$ dalam teh menggunakan metode ICP-AES Method sebesar 0,057 $\pm 0,008 \mu \mathrm{g} / \mathrm{g}$. Kandungan Cd pada sampel coklat C.2, C.3 dan sampel gula G.1 jika dibandingan dengan hasil analisis oleh Metin Gülda(12) dengan berbagai sampel agroindustri dari Turki menunjukkan hasil yang relatif lebih tinggi (lihat Tabel 2).

Tabel 2. Kadar Unsur Logam Berat Cd dalam Sampel

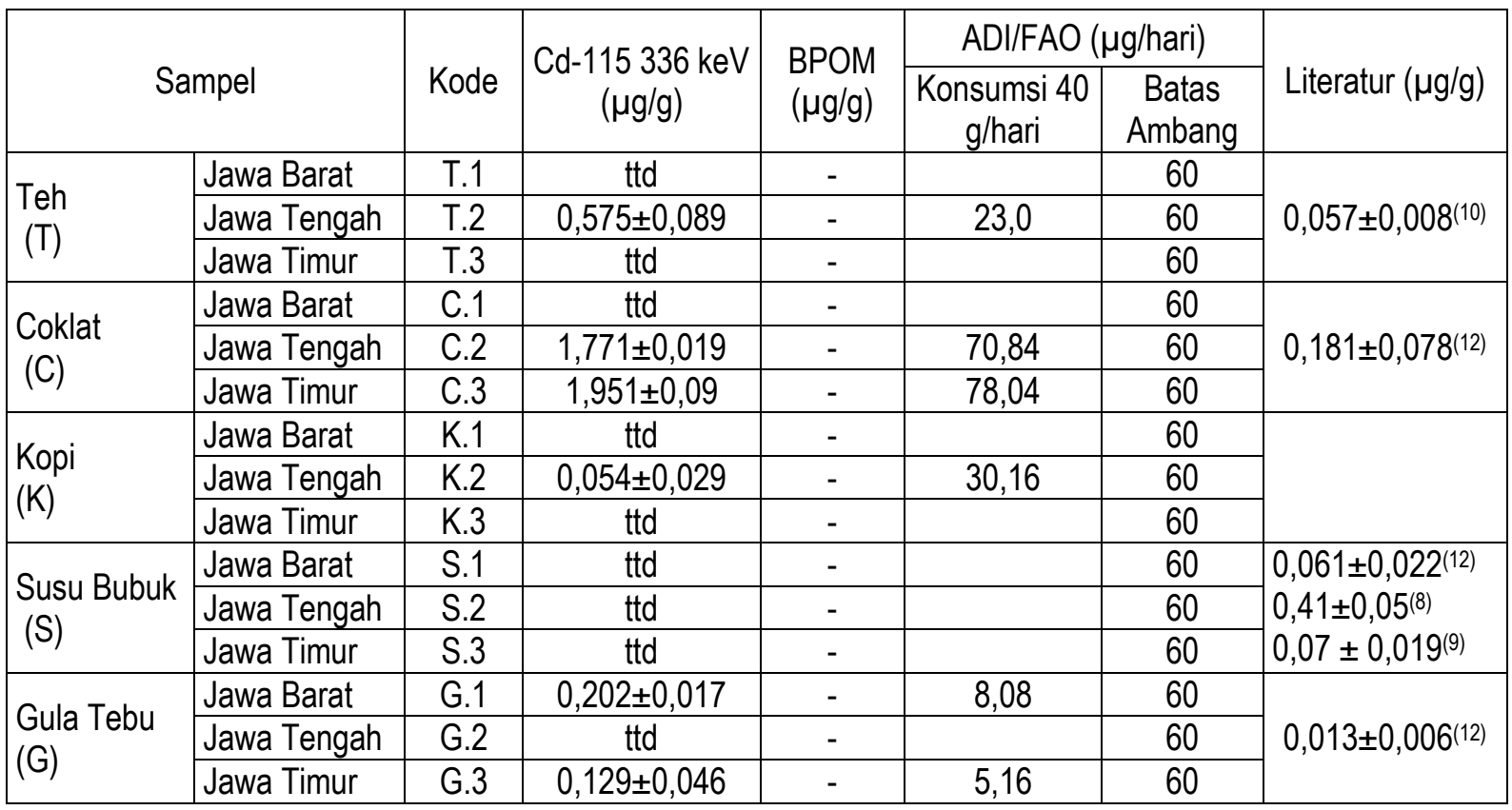

Keterangan: $\quad$ ttd : Tak terdeteksi

Kontaminasi logam Cd pada sampel coklat pada lokasi Jawa Tengah dan Jawa Timur disebabkan coklat ditanam pada jenis lahan dataran rendah dapat mengalami degradasi lahan maupun terkontaminasi logam berat dari air tanah berasal dari air sungai yang telah tercemar. Kadar logam $\mathrm{Cd}$ di tanah berada di bawah $1 \mu \mathrm{g} / \mathrm{g}^{(8)}$. Hal ini menunjukkan bahwa tanah sebagai media tanam memberikan sumbangan logam $\mathrm{Cd}$ pada tanaman yang pada akhirnya ikut terproduksi dalam proses pengolahan menjadi produk agroindustri.

\section{Kandungan Unsur Logam Berat As dalam Sampel}

Arsen (As) merupakan logam yang terdapat dimana-mana, kadarnya dalam produk agroindustri menurut BPOM seperti coklat bubuk, kopi bubuk, teh, dan gula tebu yaitu sekitar $1 \mu \mathrm{g} / \mathrm{g}$. Susu dan hasil olahannya sebesar $0,1 \mu \mathrm{g} / \mathrm{g}$. Pencemaran oleh As berasal dari industri metalurgi, gelas, pewarna dan bahan kimia selain itu juga dari kegiatan pertanian. Sumber utama As masuk ke dalam tubuh adalah makanan yang mengandung kurang dari $1 \mu \mathrm{g} / \mathrm{g}$.

Bahan makanan yang mengandung As ratusan $\mu \mathrm{g} / \mathrm{g}$ dalam jangka panjang dapat menyebabkan hiperkeratosis kulit dan hiperpigmentasi. Senyawa As dalam dosis yang sangat besar menyebabkan kerusakan 
saluran pencernaan dengan muntah-muntah dan diare berdarah, kejang otot dan kelainan jantung. Logam As dapat terdeteksi pada energi $559 \mathrm{keV}$. Hasil analisis sampel agroindustri, hanya sampel teh T.1 yang terdeteksi mengandung logam As.

Kadar As menurut baku mutu Keputusan Dirjen POM sebesar $1(\mu \mathrm{g} / \mathrm{g})^{(7)}$. Hasil penelitian dibandingkan dengan baku mutu kadar unsur logam berat As pada energi $559 \mathrm{keV}$. Pada sampel teh T.1 kadar As yang terdeteksi sebesar $0,058 \pm 0.008 \mu \mathrm{g} / \mathrm{g}$ dan masih di bawah batas ambang baku mutu. Menurut batas toleransi ADI pemasukan logam As dalam tubuh sebesar $10 \mu \mathrm{g} / \mathrm{hari}$. Apabila rata-rata orang mengkonsumsi teh perhari adalah 40 gram dan dianggap semua unsur As yang masuk ke dalam tubuh seluruhnya maka rata-rata orang menelan As sebesar 1,656 $\mathrm{\mu g} / \mathrm{hari}$. Kadar As dalam sampel T.1 tidak melampaui batas toleransi yang diizinkan menurut konsep ADI. Menurut penelitian yang telah dilakukan W.Y.Han(10) konsentrasi As dalam teh menggunakan metode ICP-AES Method sebesar 0,28 $\pm 0,03 \mathrm{mg} / \mathrm{kg}$. Hasil tersebut lebih besar dibandingkan dengan hasil analisis As dalam sampel T.1.

\section{Kandungan Unsur Logam Berat Cr dalam Sampel}

Kromium ( $\mathrm{Cr}$ ) merupakan elemen berbahaya dan dijumpai dalam kondisi oksida antara $\mathrm{Cr}$ (II) sampai $\mathrm{Cr}$ (VI), untuk kromium bervalensi tiga dijumpai di alam. Kromium enam valensi merupakan salah satu material organik pengoksida tinggi. Pada bahan makanan dan tumbuhan, mobilitas kromium relatif rendah. Unsur logam berat $\mathrm{Cr}$ masuk ke dalam tubuh melalui makanan kemudian tertumpuk di liver, limfa dan ginjal secara bersamaan dan dalam waktu yang panjang akan mengendap dan menimbulkan kanker $(8,9)$. Selain itu $\mathrm{Cr}$ juga dapat dengan mudah menyebar di dalam pembuluh darah. $\mathrm{Cr}$ sangat beracun dan berbahaya bagi kesehatan manusia.

Tabel 3. Kadar Unsur Logam Berat Cr dalam Sampel

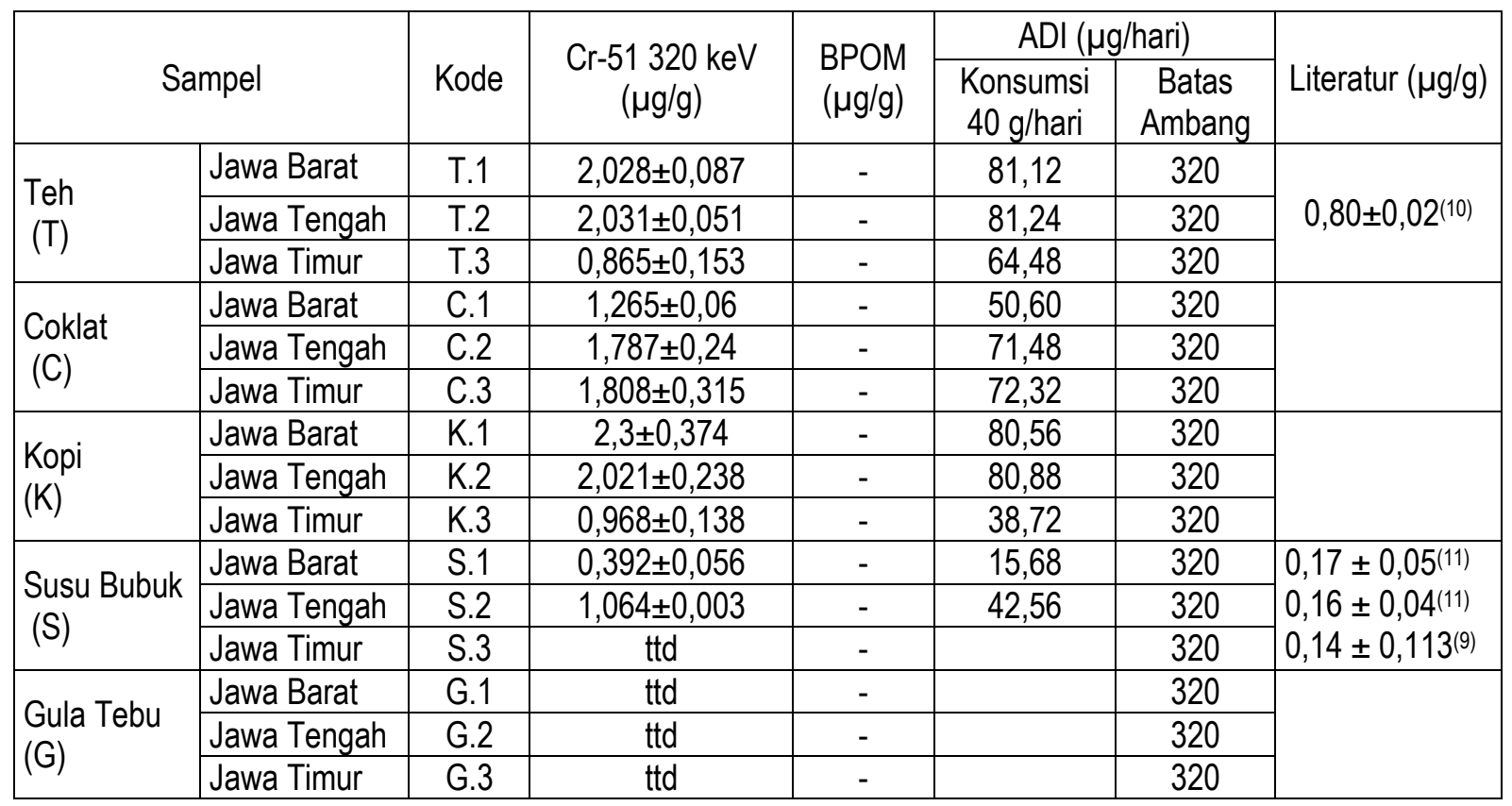

Keterangan: $\mathrm{ttd}=$ Tak terdeteksi

Pada Tabel 3 dapat dilihat bahwa unsur $\mathrm{Cr}$ terdeteksi pada semua sampel teh, coklat, kopi dan 2 sampel susu bubuk. Kadar $\mathrm{Cr}$ yang terdapat dalam sampel tersebut belum ada peraturan baku mutu menurut Keputusan Dirjen POM mengenai ambang batas kadar logam berat pada kopi, coklat, teh, susu bubuk, dan gula tebu. Menurut batas toleransi ADI pemasukan logam berat krom ke dalam tubuh $320 \mu \mathrm{g} / \mathrm{hari}$. Apabila seseorang mengkonsumsi teh merek dagang 1 sebesar 40 gram dalam sehari dan dianggap semua unsur krom yang masuk ke dalam tubuh seluruhnya maka maka $\mathrm{Cr}$ yang masuk ke dalam tubuh sebesar 85,526 $\mu \mathrm{g} / \mathrm{hari}$; seseorang mengkonsumsi coklat $C .1$ sebesar 40 gram dalam sehari maka $\mathrm{Cr}$ yang masuk ke dalam tubuh sebesar 53,390 $\mu \mathrm{g} / \mathrm{hari}$; seseorang mengkonsumsi kopi K.1 sebesar 40 gram dalam sehari maka $\mathrm{Cr}$ yang masuk ke dalam tubuh 
sebesar 96,997 $\mu \mathrm{g} / \mathrm{hari} ;$ seseorang mengkonsumsi susu S.1 sebesar 40 gram dalam sehari maka Cr yang masuk ke dalam tubuh sebesar 15,68 $\mathrm{\mu g} / \mathrm{hari}$. Kadar teh, coklat, kopi, dan susu bubuk dalam hasil penelitian ini tidak melampaui batas toleransi yang diizinkan menurut konsep ADI. Menurut penelitian yang telah dilakukan W.Y.Han ${ }^{(10)}$ konsentrasi $\mathrm{Cr}$ dalam teh menggunakan metode ICP-AES Method sebesar 0,80 $\pm 0,02 \mathrm{mg} / \mathrm{kg}$. Hasil tersebut lebih kecil jika dibandingkan dengan hasil analisis pada sampel T.1, T.2 dan T.3. Hasil analisis $\mathrm{Cr}$ pada sampel S.1 dan S.2 relatif lebih tinggi jika dibandingkan dengan data analisis yang dilakukan oleh peneliti lain melebihi hasil analisis susu dari negara Italia yaitu $0,14 \pm 0,113 \mathrm{mg} / \mathrm{kg}^{(9)}$, dari Negara China $(0,16 \pm 0,04$ $\mathrm{mg} / \mathrm{kg})^{(11)}$ dan Negara Jepang $(0,17 \pm 0,05 \mathrm{mg} / \mathrm{kg})^{(11)}$, Hal ini dimungkinkan karena sampel yang dianalisis dan metode yang digunakan berbeda dengan FAAS.

\section{Kandungan Unsur Logam Berat Co dalam Sampel}

Tubuh manusia memerlukan unsur logam kobalt (Co) dalam jumlah sangat sedikit untuk proses pembentukan sel darah merah. Kobalt merupakan komponen vitamin $B_{12}$. Asupan kobalt dalam jumlah banyak dapat menyebabkan sel darah merah menjadi tinggi, pergelangan kaki membengkak terutama pada anak-anak yang sedang mengalami pertumbuhan. Kontaminasi logam Co di tempat kerja menyebabkan iritasi pernapasan dan reaksi hipersensitivitas kulit.

Kadar Co yang terdapat dalam sampel tersebut belum ada peraturan baku mutu menurut Keputusan Dirjen POM mengenai ambang batas kadar logam berat pada kopi, coklat, teh, susu bubuk, dan gula tebu. Menurut batas toleransi ADI pemasukan logam berat kobalt ke dalam tubuh $1000 \mu \mathrm{g} / \mathrm{hari}$. Hasil analisis menunjukkan kadar Co pada energi $1332 \mathrm{keV}$ dalam sampel teh T.2 sebesar 0,478 $\pm 0,03 \mu \mathrm{g} / \mathrm{gr}$ dan dalam sampel gula G.3 sebesar 2,811 $\pm 0,461 \mu \mathrm{g} / \mathrm{gr}$. Apabila seseorang mengkonsumsi teh sebesar $40 \mathrm{gram}$ dalam sehari maka logam berat kobalt yang masuk ke dalam tubuh sebesar 17,12 $\mu \mathrm{g} / \mathrm{hari}$; seseorang mengkonsumsi gula tebu sebesar 40 gram dalam sehari maka Co yang masuk ke dalam tubuh sebesar 112,44 $\mu \mathrm{g} / \mathrm{hari}$. Jumlah kadar teh, dan gula tebu tidak melampaui batas toleransi yang diizinkan menurut konsep ADI. Menurut penelitian yang telah dilakukan W.Y.Han ${ }^{(10)}$ konsentrasi Co dalam teh menggunakan metode ICP-AES Method sebesar $0,18 \pm 0,02 \mathrm{mg} / \mathrm{kg}$. Hasil tersebut lebih kecil jika dibandingkan dengan hasil analisis pada sampel T.2 dan G.3.

Keracunan Co disebabkan adanya perpindahan Co berasal dari tanah, air, dan udara yang diserap oleh akar, daun tanaman. Logam Co memiliki daya racun yang tinggi terhadap tumbuhan dan kebanyakan tumbuhan memerlukan cairan elemen ini dalam konsentrasi tidak lebih dari $1 \mu \mathrm{g} / \mathrm{gr}\left({ }^{(8)}\right.$.

Kandungan logam berat $\mathrm{Hg}$, As, $\mathrm{Cr}$, Co dan $\mathrm{Cd}$ pada berbagai sampel agroindustri berasal dari perpindahan unsur-unsur $\mathrm{Hg}, \mathrm{As}, \mathrm{Cr}$, Co dan $\mathrm{Cd}$ yang berasal dari udara, tanah, dan udara yang diserap sebelum diproses menjadi produk jadi. Selain itu, kontaminasi dapat terjadi pada saat pengolahan bahan mentah, penggunaan pestisida anorganik yang mengandung $\mathrm{Hg}, \mathrm{As}, \mathrm{Cr}$, Co dan $\mathrm{Cd}$ sehingga akan terakumulasi dalam tanaman melalui akar, batang, daun maupun buahnya yang akan mempengaruhi hasil tanaman, proses pengawetan produk industri yang menggunakan obat anti jamur serta hasil migrasi dari bahan pengemasnya ${ }^{(11,12)}$.

\section{Limit Deteksi}

Hasil batas deteksi alat disajikan pada Tabel 4. Batas deteksi alat meliputi $L_{C}$ (Critical Limit) merupakan batas putusan yang artinya tingkat net signal yang mungkin diduga telah terdeteksi, $L_{D}$ (Detection Limit) merupakan batas deteksi yang artinya tingkat net signal yang sebenarnya yang mungkin diharapkan mulai mendeteksi, dan $L_{Q}$ (Determination Limit) merupakan batas ketentuan penentuan yang artinya tingkat net signal dimana pengukuran presisi akan memuaskan untuk penentuan kuantitatif dan FOM (Figure Of Merit) adalah kemampuan alat ukur radioaktivitas mulai mendeteksi(13).

Batas deteksi untuk masing - masing logam ada lima karena blanko dilakukan 5 kali. $L_{C}$ (Critical Limit) atau batas putusan pada penelitian ini mencapai orde $10^{-3} \mu \mathrm{g} / \mathrm{g}$ atau sampai orde $\mathrm{ppb}\left(10^{-9}\right), L_{D}$ (Detection Limit) atau batas deteksi mencapai orde $10^{-4} \mathrm{\mu g} / \mathrm{g}$ atau sampai orde $10^{-1} \mathrm{ppb}$, sedangkan $L_{Q}$ (Determination Limit) atau batas ketentuan penentuan mencapai orde $10^{-3} \mathrm{\mu g} / \mathrm{g}$ atau sampai orde ppb (10-9). FOM (Figure Of Merit) atau mulai dideteksi sampel dalam alat ukur radioaktivitas yaitu pada 0,04114 detik untuk As pada Energi $559 \mathrm{keV}$; 
0,00716 detik untuk $\mathrm{Hg}$ pada energi 68\&77 keV; 0,02649 detik untuk $\mathrm{Cd}$ pada energi $336 \mathrm{keV}, \quad 0,01654$ detik untuk $\mathrm{Cr}$ pada tenaga $320 \mathrm{keV}$, dan 0,03460 detik untuk Co pada tenaga $1332 \mathrm{keV}$.

Tabel 4. Data Batas Deteksi dan FOM Alat

\begin{tabular}{|l|c|c|c|c|c|c|c|c|}
\hline \multirow{2}{*}{ Unsur } & \multirow{2}{*}{$\mathrm{K}$} & \multicolumn{2}{|c|}{$\mathrm{LC}$} & \multicolumn{2}{c|}{$\mathrm{LD}$} & \multicolumn{2}{c|}{$\mathrm{LQ}$} & $\begin{array}{c}\text { FOM } \\
\text { (Detik) }\end{array}$ \\
\cline { 3 - 8 } & & $\mathrm{Cps}$ & $\mu \mathrm{g} / \mathrm{g}$ & $\mathrm{cps}$ & $\mu \mathrm{g} / \mathrm{g}$ & $\mathrm{cps}$ & $\mu \mathrm{g} / \mathrm{g}$ & (D) \\
\hline${ }^{76} \mathrm{As}(559 \mathrm{KeV})$ & 15,598 & 0,03936 & 0,00252 & 0,07896 & 0,05408 & 0,204 & 0,00131 & 0,04114 \\
\hline${ }^{115} \mathrm{Cd}(336 \mathrm{KeV})$ & 0,44575 & 0,01804 & 0,00804 & 0,03619 & 0,01613 & 0,11 & 0,49033 & 0,02649 \\
\hline${ }^{51} \mathrm{Cr}(320 \mathrm{KeV})$ & 7,4952 & 0,00433 & 0,03245 & 0,00869 & 0,06510 & 0,026 & 0,19787 & 0,01654 \\
\hline${ }^{60} \mathrm{Co}(1332 \mathrm{KeV})$ & 0,09820 & 0,00285 & 0,00028 & 0,00295 & 0,00290 & 0,0174 & 0,00171 & 0,03460 \\
\hline${ }^{197} \mathrm{Hg}(77 \mathrm{KeV})$ & 0,6964 & 0,20372 & 0,14187 & 0,40868 & 0,28460 & 1,2422 & 0,86507 & 0,00716 \\
\hline
\end{tabular}

\section{KESIMPULAN}

Menurut hasil penelitian dan pembahasan yang telah dilakukan maka dapat diambil kesimpulan:

1. Hasil analisis dalam sampel teh terdeteksi unsur logam berat $\mathrm{Cd}(0,575 \pm 0,089 \mu \mathrm{g} / \mathrm{g})$, As $(0,058 \pm 0,008$ $\mu \mathrm{g} / \mathrm{g}), \operatorname{Cr}(0,865 \pm 0,153-2,031 \pm 0,051 \mu \mathrm{g} / \mathrm{g})$, dan Co $(0,478 \pm 0,03 \mu \mathrm{g} / \mathrm{g})$, sampel coklat terdeteksi unsur logam berat $\mathrm{Cd}(1,771 \pm 0,019-1,951 \pm 0,09 \mu \mathrm{g} / \mathrm{g})$ dan $\mathrm{Cr}(1,265 \pm 0,06-1,808 \pm 0,315 \mu \mathrm{g} / \mathrm{g})$, sampel kopi terdeteksi unsur logam berat $\mathrm{Cd}(0,054 \pm 0,029 \mu \mathrm{g} / \mathrm{g}), \mathrm{Cr}(0,968 \pm 0,138-0,230 \pm 0,374 \mu \mathrm{g} / \mathrm{g})$, dan $\mathrm{Hg}$ $(3,719 \pm 0,423 \mu \mathrm{g} / \mathrm{g})$, sampel gula tebu terdeteksi unsur logam berat $\mathrm{Cd}(0,129 \pm 0,046-0,202 \pm 0,017 \mu \mathrm{g} / \mathrm{g})$ dan $\mathrm{Co}(2,811 \pm 0,461 \mu \mathrm{g} / \mathrm{g})$, sedangkan sampel susu bubuk terdeteksi unsur logam berat $\mathrm{Cr}(0,392 \pm 0,056$ $1,064 \pm 0,003 \mu \mathrm{g} / \mathrm{g})$.

2. Berdasarkan pada SK Dirjen POM Nomor 03723/B/SK/VII/1989, kadar Hg dalam sampel K.1 sebesar $3,719 \pm 0,423 \mu \mathrm{g} / \mathrm{g}$ di atas batas ambang baku mutu $(0,03 \mu \mathrm{g} / \mathrm{g})$, sedangkan unsur As dalam sampel T.1 sebesar $0,058 \pm 0.008 \mu \mathrm{g} / \mathrm{g}$ di bawah batas ambang baku mutu $(1 \mu \mathrm{g} / \mathrm{g})$.

3. Berdasarkan batas ambang konsumsi harian logam berat dalam tubuh menurut ketentuan ADI (anggapan konsumsi sampel 2x20 g/hari) yang dikeluarkan oleh FAO/WHO, maka kadar unsur Hg dalam sampel K.1 di atas ambang ADI. Kadar unsur As dalam sampel T.1 di atas ambang ADI.

4. Berdasarkan batas ambang konsumsi harian logam berat dalam tubuh menurut ketentuan ADI (anggapan konsumsi sampel 2x20 g/hari), maka kadar unsur $\mathrm{Cr}$ dalam semua sampel Teh, Coklat Bubuk, Kopi, dan Susu Bubuk di bawah ambang ADI. Kadar unsur Cd dalam sampel T.2, C.2 dan C3, K.2, dan G.1 dan G.3 semua di bawah ambang ADI. Kadar unsur Co dalam sampel T.2, dan G.3 di bawah ambang ADI.

5. Berdasarkan hasil analisis sampel agroindustri di berbagai Negara, hasil analisis $\mathrm{Hg}, \mathrm{Cd}, \mathrm{As}, \mathrm{Cr}$, dan $\mathrm{Co}$ pada sampel agroindustri pada penelitian ini menunjukkan hasil yang relatif baik dengan perbandingan hasil ada yang melebihi dan ada yang di bawah dari hasil penelitian lain.

\section{DAFTAR PUSTAKA}

1. ALPER BABA AND GOKMEN TAYFUR, "Groundwater contamination and its effect on health in Turkey", Journal Environmental Monitoring Assessment, Springer (2011).

2. ADI-FAO/WHO 2008, "Bahaya Pencemaran Logam Berat Dalam Air", http://adinfobogor.com/2008/01/ bahaya-pencemaran-logam-berat-dalam-air31.html (Diakses 11 Juni 2008)

3. A. TAFTAZANI, SUMINING, DARMADJI, "Studi Perbandingan Metode Analisis SS-AAS dan AAN untuk Analisis Logam Cd, Cr, Cu dalam Sampel CRM Oyster Tissue dan Sargassum Fulvellum”,Yogyakarta: P3TM-BATAN, (2004) halaman 99 s.d. 105.

4. G. ERDTMANN AND W. SOYKA, "The Gamma Ray of The Radionuklides Tables for Applied Gamma Ray Spectrometry", New York: Weinheim, (1979).

5. DAVID TIN WIN, Neutron Activation Analysis (NAA), Faculty of Science and Technology, Assumption University Bangkok, Thailand, AU J.T. 8(1): (Jul. 2004), 8-14. 
Evaluasi $\mathrm{Hg}, \mathrm{Cd}$, Co, Cr, dan As dalam Sampel Produk Agroindustri Berdasarkan Keputusan BPOM dan ADI (Accept Daily Intake) (Sri Murniasih, dkk.)

6. SRI MURNIASIH, AGUS TAFTAZANI, "Kandungan Logam Berat Dalam Sampel Minyak Goreng, Kecap dan Saus Tomat Dibandingkan Dengan Baku Mutu BPOM dan ADI", Prosiding Seminar Nasional AAN 2009, FAANI-BATAN ISSN 2085-2797, Yogyakarta 20 Oktober 2009, 175 - 182.

7. ANONIM, "Keputusan Direktur Jenderal Pengawasan Obat dan Makanan (POM) Nomor 03723/B/SKVII/1989" (1989).

8. ABDALLAH, M.I.M., "Evaluation Of Some Heavy Metal Residues In Whole Milk Powder Used At Confectionery Plants Regarding Their Public Health Significance", Agricultural Research Center, Giza, Egypt, (2004).

9. ANIELLO ANASTASIO, "Heavy Metal Concentrations in Dairy Products from Sheep Milk Collected in Two Regions of Southern Italy" Acta Vet Scand (2006); 47 (1), 69 - 74

10. HAN, .W.Y, SHI, Y.-Z, MA, L.-F, RUAN, J.-Y., 2005, "Arsenic, Cadmium, Chromium, Cobalt, and copper in different Types of Chinese Tea", Springer Science, (2005) 272 - 277.

11. LIN-QIANG QIN, XIAO-PING WANG, WEI LI, XING TONG AND WEI-JUN TONG, "The minerals and heavy metals from cow's milk from China and Japan, Journal of Health Science 55(2) (2009), 300 - 305.

12. METIN GÜLDA, ADNAN F. DA DELEN AND GÜNNUR F. BIRICIK, "Determination and comparison of some trace elements in different chocolate types produced in Turkey", Food Control and Central Research Institute, Ministry of Agriculture, Bursa, Turkey, (2008).

13. SINAGA SITI MORIN, "Perspektif pengawasan makanan dalam kerangka keamanan makanan dan untuk meningkatkan kesehatan", FMIPA Universitas Sumatra Utara, (2004).

14. ROY BATEMAN, "Capacity Building Programme on Pesticide Residues and Other Harmful Substances in Cocoa in Africa" Project Preparation Grant Report, (2010). 